\title{
Relationship between the Risk of Falling and Prescribed Medication in Community-dwelling Elderly Subjects
}

\author{
Pilar Pérez-Ros ${ }^{1}$, Francisco Martínez-Arnau ${ }^{2,}$, Esther Navarro-Illana ${ }^{1}$,Inmaculada Tormos-Miñana ${ }^{1}$, \\ Francisco José Tarazona-Santabalbina ${ }^{1,3}$ \\ ${ }^{1}$ Facultad de enfermería Universidad Católica de Valencia San Vicente Martir, Valencia, 46007, España \\ ${ }^{2}$ Departamento de Fisioterapia, Universitat de Valencia. Valencia, 46010, España \\ ${ }^{3}$ Hospital Universitario de la Ribera, Alzira, 46600, Valencia. España \\ *Corresponding Author: francisco.m.martinez@uv.es
}

Copyright (C) 2013 Horizon Research Publishing All rights reserved.

\begin{abstract}
Introduction: The risk of falling increases with age. A third of the population over 65 has one or more falls per year. Objetive: to know the relationship between drug prescription and falls in the elderly. Materials and Methods: a study was carried out through a community intervention in individuals $\geq 70$ years of age. Results: The sample was composed of 249 participants, 160 women (64\%), with a mean age of 74.47 years (SD 5.33). During the 12 months prior to the study, the mean of falls per person was 0.5 (SD 0.94 ), the mean of the risk factors was 2.73 (SD 1.4) and the mean of the medication prescribed was 4.2 (SD 3.0). The percentage of the reduction of falls after the study was $12 \%$. The amount of medication prescribed correlated with the incidence of falls before and after the study, $\mathrm{r}=0.193$, $\mathrm{p}=0.002$ y $\mathrm{r} 2=0.170, \mathrm{p}=0.009$, respectively. Prior to the study, the individuals who were prescribed beta-blockers and antidepressants, had a fall incidence of 0.74 (SD 1.14) and 1.22 (SD 1.09), respectively, however after the intervention there was no relationship between drug prescription and falls. Conclusions: the fall prevention community program was effective since it prevented the negative effects of medication on falls. An interdisciplinary community intervention reduces the global incidence of falls and the incidence of falls related to some specific medication.
\end{abstract}

Keywords Elderly, Polypharmacy, Risk Factors, Falls, Geriatric Assessment

\section{Introduction}

The risk of falling increases with age. Despite their personal independence and autonomy, a third of the population over 65 has one or more falls per year. This percentage is approximately $35 \%$ in individuals over 75 and $50 \%$ in individuals over 80 [1]. Moreover, having had a fall increases the risk of further falls. In fact, more than half of the elderly who have had a fall will have a new one within six months [2].

As a consequence of these falls, between 20-30\% suffer injuries, which reduce their mobility and independence, and increase the risk of premature death [3,4]. A lower percentage requires specialized attention due to fractures. $20 \%$ of the elderly people who fall become institutionalized or die [5].

Together with balance instability and gait alterations, falls constitute one of the most important geriatric syndromes and they are the second cause of death worldwide due to accidental injuries [6].

Generally, falls are more frequent in women, although this tendency becomes similar with age. The mortality rate due to falls increases exponentially with age in both genders and in all racial/ethnic groups, mainly after the age of 75. [7]

From a public health perspective, falls in the elderly are considered a biopsychosocial problem due to their medical, psychological, social and economic consequences [8]. It is estimated that in 2020 the cost of social healthcare due to falls will be approximately 30.000 million euros, as $20 \%$ of falls require medical attention, constituting $10 \%$ of Emergency Department attendances and 6\% of urgent hospitalizations in the elderly [9]. In addition, there is a high morbidity since falls are directly related to a decreased mobility and ability to perform daily life activities. This increases their fear of falling again, favors a low selfconfidence and the apparition of post-fall syndrome psychological consequences [10]. The risk of caregiver dependence and/or institutionalization, and family, social and health repercussions also increase.

In general terms, we classify falls in low or high impact, based in the amount of energy involved. Low-impact falls are falls from standing and are characterized by minimal injury of soft tissues. This type of falls is frequent in children and in the elderly; they often cause isolated fractures. High-impact falls are associated to high-energy trauma and they affect soft tissue and also organs; they are associated to more severe fractures [11]. Approximately 30- 
$50 \%$ of the falls produce soft tissue injuries and $10 \%$ produce fractures or head trauma, both related to a higher mortality rate (between $25-46 \%$ ) within the following year [12].

Tinetti established the risk factors related with falls, emphasizing the existence of cognitive impairment, presence of at least two chronic illnesses, gait and balance alterations, and low BMI (Body Mass Index) [13].

Furthermore, intrinsic and extrinsic risks were described. The former are related to the ageing process and affect the balance, the proprioceptive, vestibular and visual functions of the cerebellum [14]. The individual's musculoskeletal function and the cognitive status are also important [15]. Extrinsic risks are environmental (home, the street or public transport) and they are contributing factors to the intrinsic risks [16].

The risk of falling in an individual increases with the number of risk factors, from $8 \%$ in people with no risk factors, to $78 \%$ in individuals with 4 or more risk factors [17]. There are some risk factors related to a higher number of falls, as previously mentioned, like the use of concomitant medication and alterations in muscle strength, balance and gait [18].

The increased risk of falling, and fall-related injuries associated with aging, appeared to be due to the accumulation of other risk factors rather than being intrinsic to aging itself. A number of specific diseases and a general index of health status have been shown to be associated with increased incidence of falls [19]

Together with these, we can observe frequent comorbidity like hypertension [ 20 ], diabetes[21 ], cardiovascular disease[22], osteoporosis[23] and insomnia [24]. These pathologies are associated mostly with the use of more than 4 different drugs (polypharmacy) [25].

$14.9 \%$ of people older than 65 state to have had a fall over a 1 -year period, with physical consequences. In $50 \%$ of the falls, contusions or soft tissue injuries occur, causing pain and impairment for the daily life activities. $10-15 \%$ of the falls involve minor injuries [26]. The major consequences are fractures. $90 \%$ of hip, pelvis and wrist fractures in the elderly are associated to low-impact falls, which are mainly domestic. The hip fracture is the main related cause of mortality, and it is due to comorbidity and immobility complications [27]. Men present a higher mortality than women within twelve months following a hip fracture [28]. $90 \%$ of the hip fractures are due to falls. The related risk factors are osteoporosis and repeated lowimpact falls [29]. Other types of fall-related fractures are vertebral and wrist fractures which, on many occasions, increase the dependence due to neuralgia, paralysis and paresthesia [30]. Head traumas are also fall consequences in the elderly due to their inability to stop the fall with their upper limbs or due to fainting related to polypharmacy [31]. They are related to a higher index of hospitalizations and death [32].

One of the psychological consequences is the post-fall syndrome, i.e. the short and long term effects which produce restrictive attitude and behavior for physical and social activities due to the fear of falling [33].

The socio-economic consequences are both the direct and indirect costs. The elderly who have had falls make more use of the Primary Care and Emergency services. Hospital admission after a fall is linked to a higher institutionalization due to immobilization and to an increase in the expenses due to home care [34].

\subsection{Drugs, Polypharmacy and Falls}

This polypharmacy is an independent factor for higher risk of falls (OR 1.14; 95\% CI 1.02, 1.27; $\mathrm{p}=0.027$ ) [35]. Moreover, certain drugs are related to a higher risk of falls [36.], i.e. beta-blockers, drugs with orthostatic hypotension effects, benzodiazepines, antidepressants, antiepileptic drugs, anti-Parkinson medication, opiates and urinary antispasmodic drugs [37,38].

Many commonly used drugs produce an anticholinergic effect; antihistamines, antiemetics, antispasmodics, biperidene, tricyclic antidepressants, oxybutinine, etc. [39]. However, they also have side effects [40] such as delirium, dry mouth, blurred vision, constipation or paralytic ileus, urinary retention, gait alterations and acute glaucoma attack, mainly in the elderly due to their unique characteristics [41].

The use of medication is affected by pharmacokinetic changes related to renal and hepatic function decline, decreased muscle mass and increased adipose tissue [42] in the elderly. Consequently, with the same drug concentration, we can observe different significant responses to some drugs [43].

\subsection{Relationship between Specific Drug Groups and Incidence of Falls}

\subsubsection{Benzodiazepines}

Many studies link a higher risk of falls with benzodiazepines [ 44] (OR=1.48 [95\% CI 1.23, 1.77]), mainly in women $(\mathrm{OR}=1.23$ [95\% CI 1.09, 1.63]).

Hip fractures are one of the consequences of falling $(R R=1.7)$, also directly related to the use of benzodiazepines; the higher the daily dose, the higher risk of falling $(\mathrm{OR}=3.4[95 \%$ CI $1.0,11.5])$. The concomitant use of different benzodiazepines is also an associated risk factor $(\mathrm{OR}=2.5$ [95\% CI 1.3, 4.9]) [45].

\subsubsection{Cardiovascular Disease}

There is a higher risk of falls with the intake of drugs with hypotensive effect, like diuretics (OR 1.08; 95\% CI 01.02, 01.16), and beta-blockers (OR 0.93; 95\% CI 0.77 , 1.11) [46].

\subsubsection{Antidepressants}

Depression and the use of antidepressants constitute a risk factor for the incidence of falls in the elderly.

There is some controversy with regards to the causes that relate antidepressants to a higher number of falls.[47, 48] 
The main cause of this relation is orthostatic hypotension which, together with other risk factors, has an impact on falls. Some of these other factors are blurred vision, strength and muscle tone loss, constipation, urinary retention, confusion, anxiety or cardiovascular problems $[49,50]$.

Recent studies link a higher risk of falls with the intake of serotonin uptake inhibitors ( $\mathrm{OR}=2.4$ [95\% CI 2.0, 2.7]), compared to that calculated for tricyclic antidepressants $(\mathrm{OR}=2.2[95 \%$ CI $1.8,2.8])$. Nevertheless, both present a hip fracture risk related to falls [51].

\subsubsection{Antiepileptic DRUGS}

There is little data due to the scarce number of elderly patients treated with this medication. However, patients present weakness, ataxia and sedation symptoms. A relationship between antiepileptic medication and a higher risk of falling has been described in women $(\mathrm{OR}=2.56[95 \%$ CI 1.49, 4.41]) [52].

\section{Materials and Methods}

We carried out a community intervention; a longitudinal prospective randomized experimental study, in order to assess the effectiveness of a program aimed at the elderly population, focused on fall prevention in the community.

We had a sample of 249 individuals from the Primary Care community health centers of the towns of Alberic, Algemesí, Albalat de la Ribera, Alginet, Alzira I, Benifaio, Carcaixent, Carlet, Guadasuar and Sueca, in Valencia (Spain), which belong to the Health Department of $\mathrm{La}$ Ribera. The inclusion criteria were: $\geq 70$-yearl-old men and women, independent mobilization or mobilizing with aids (not assisted by other people), residing within the area of $\mathrm{La}$ Ribera, having signed and informed consent form. The exclusion criteria were: bedridden individuals, chronic terminally-ill patients or with a life expectancy under 6 months, institutionalized patients, total visual or hearing impairment, patients with severe psychiatric problems or with severe or moderate cognitive deterioration, and not having signed the informed consent form.

We carried out a community intervention on each individual every trimester for a year. We raised their awareness about the importance of living in a risk-free environment to prevent falls, and we gave them a leaflet with physical exercises to improve their proprioception, balance and gait. We also performed an evaluation of the variables each trimester.

On our first visit, we enquired about the number of falls in the previous 12 months, number of risk factors related to falls, previous fractures, and we did a functional evaluation using the Barthel index, which assesses the independence to carry out daily life activities (Independence $\geq 60$ over 100) [53]. Moreover, we assessed their balance and gait using the Tinetti scale [7]. This scale has two sections, where a total score of 12 points in the gait, and a total score of 16 in the balance, can be obtained. A score below 9 in the gait and 12 in the balance indicates risk of falling. An overall score of $\leq 21$ over 28 represents a high risk of falling. We also used the European Quality of Life Scale EQ-5D [54], subjective (0-10) and objective (0-1), as well as the Mini Mental State Examination (MMSE) [55] (Deterioration < 26 over 35 ). Finally we enquired about the most common chronic pathologies related to falls, amount of daily medication prescribed and main drugs directly related with falls (beta-blockers and alpha-blockers). The rest of antihypertensive drugs with no orthostatic hypotension effect were grouped into one variable (antihypertensives), since the risk of falling does not differ among ACE inhibitors, ARBs and calcium antagonists [56]

In the following visits we measured the different variables and reinforced the information previously given. We also asked about the falls suffered in the three previous months and their consequences.

\subsection{Ethical Considerations}

This study was approved by the research ethics committee of the Hospital Universitario de la Ribera (University Hospital of La Ribera) and each participant signed an informed consent form to be included in the study and for posterior use of statistical data.

\subsection{Statistical Analysis}

The categorical variables were presented in percentages and the quantitative variables were presented as mean, standard deviation and $95 \%$ confidence interval.

In order to analyze the relationship between each fall risk index and comorbidities or drugs, variables were compared using Student's t-test, Pearson's correlation coefficient and c2-test as appropriate.

The values of the different variables were introduced in a Microsoft Excel spreadsheet version 2003 and the statistical data was carried out using SPSS program for Windows version 19.0.

\section{Results}

The mean age of the participants was 74.47 (SD 5.33). There were 160 women (64\%) and 89 men (35.7\%).

Table 1 shows the main variables. There is a high prevalence of arterial hypertension (59.4\%), hyperlipidemia (44.2\%) and type II diabetes (24.5\%).

The mean score in the Barthel index was 94.2 (SD 10.4), most of the participants were independent in their daily life activities. The mean score in the Tinetti scale was 26.3 (SD 3.0) and the mean in EQ-5D was 7.2 (SD 2.3) subjective quality of life and 0.83 (SD 0.19) objective quality of life. The mean score in the MMSE was 27.0 (SD 3.7).

The mean of the falls in the 12 months prior to the study was 0.49 (SD 0.93), with a mean of 2.73 (SD 1.4) risk 
factors and 4.2 (SD 3.0) drugs prescribed per person.

Table 1. Characteristics of the participants.

\begin{tabular}{|c|c|}
\hline Age (years) & $74.47(5.33)$ \\
\hline Sex & 우 $160(64.3 \%){ }^{7} 89(35.7 \%)$ \\
\hline \multicolumn{2}{|l|}{ Functional scales } \\
\hline Barthel & $94.2(10.4)$ \\
\hline Tinetti & $26.2(3.0)$ \\
\hline Objective EQ5D & $0.83(0.19)$ \\
\hline Subjective EQ5D & $7.2(2.3)$ \\
\hline $\begin{array}{l}\text { Mini-Mental State } \\
\text { Examination }\end{array}$ & $27.0(3.7)$ \\
\hline \multicolumn{2}{|l|}{ Comorbidity } \\
\hline Hypertension & $148(59.4 \%)$ \\
\hline Type II Diabetes Mellitus & $61(24.5 \%)$ \\
\hline Hyperlipidemia & $110(44.2 \%)$ \\
\hline Smoking & $23(9.2 \%) \operatorname{Ex} 45(18.1 \%)$ \\
\hline $\begin{array}{l}\text { Chronic Obstructive } \\
\text { Pulmonary Disease }\end{array}$ & $20(8 \%)$ \\
\hline \multicolumn{2}{|c|}{ Fall-related factors } \\
\hline $\begin{array}{c}\text { Falls in the previous } \\
12 \text { months }\end{array}$ & $0.5(0.94)$ \\
\hline Num. risk factors & $2.73(1.4)$ \\
\hline Num. previous fractures & $0.29(0.74)$ \\
\hline Drugs prescribed & $4.2(3.0)$ \\
\hline
\end{tabular}

The most commonly prescribed drugs were benzodiazepines $(28.9 \%)$ and beta-blockers $(21.7 \%)$. There were no participants taking opiates (Table 2).
Table 2. Drugs related to risk of falls

\begin{tabular}{|cc|}
\hline Antiresorptive - Vitamin D & $19(7.6 \%)$ \\
\hline Beta-blockers & $54(21.7 \%)$ \\
\hline Alpha-blockers & $7(2.8 \%)$ \\
\hline Neuroleptics & $1(0.4 \%)$ \\
\hline Benzodiazepines & $72(28.9 \%)$ \\
\hline Antidepressants & $9(3.6 \%)$ \\
& \\
\hline
\end{tabular}

$47 \%$ of the individuals were on 3 or less different drugs daily, whereas $53 \%$ were taking 4 different drugs or more.

The participants with hypertension were taking more drugs

4.89 (SD 2.92) than those who were not hypertensive 3.13 (SD 2.77), with a mean difference of 1.75 (95\% CI, $1.04-2.77, \mathrm{p}<0.001)$. This was also been observed in diabetic individuals 5.21 (SD 3.13), whereas the nondiabetic had a mean of 3.84 (SD 2.86), with a mean difference $1.38(95 \%$ CI, 0.52-2.23, $\mathrm{p}=0.02)$. At the beginning of the study, hypertensive participants had a fall incidence 0.54 (SD 0.98), similar to those who were not hypertensive 0.45 (SD 0.91), with a mean difference 0.999 (95\% CI, 0.139-0.336, $\mathrm{p}<0.414)$. However, after 12 months, the hypertensive participants had a fall incidence 0.37 (SD 0.77 ), inferior to the non-hypertensive 0.56 (SD 0.65), with a mean difference 0.188 (95\% CI, 0.004-0.372, $\mathrm{p}=0.04)$. This was not observed in the diabetic individuals, where the fall incidence is no different.

Women presented a higher fall incidence 0.61 (SD 1.04) than men 0.27 (SD 0.65), with a mean difference of 0.337 (95\% CI, 0.13-0.55, $\mathrm{p}=0.002$ ). However, at the end of the study, this difference disappears being 0.46 (SD 0.73) in women and 0.43 (SD 0.69) in men, with a mean difference $0.30(95 \%$ CI, 0.16-0.22, $\mathrm{p}=0.753)$.

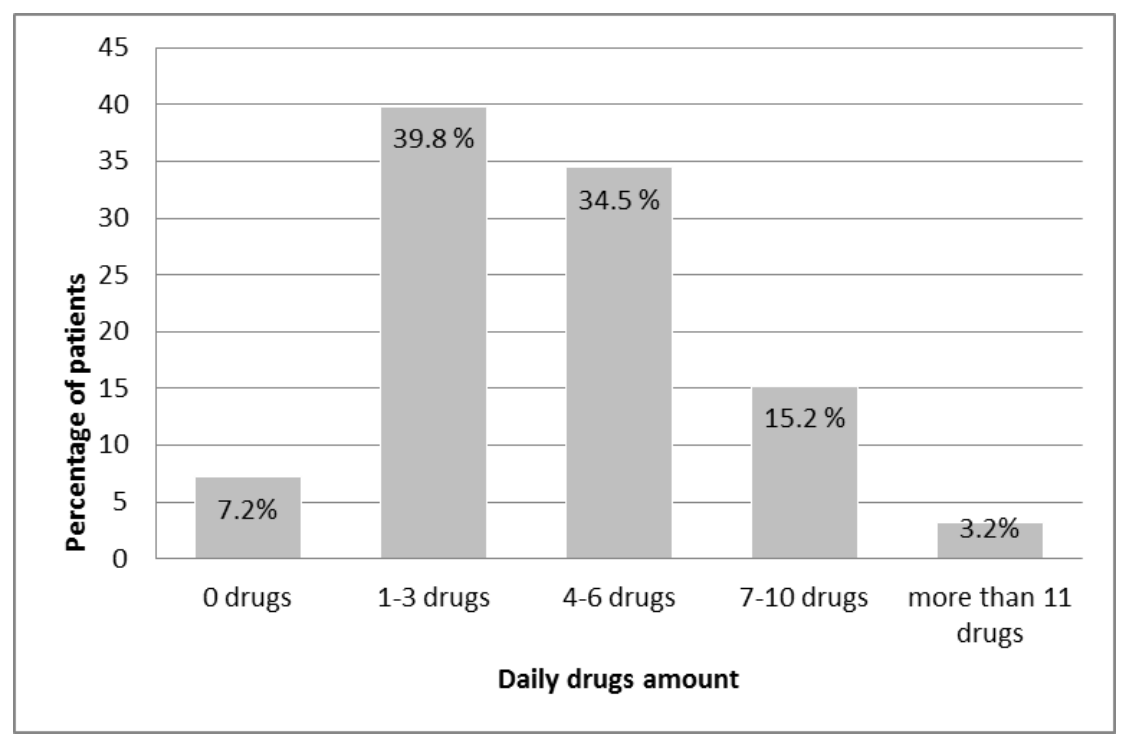

Figure 1. Daily drug use 
The number of drugs prescribed correlates with the incidence before and after the study $\mathrm{r}=0.19, \mathrm{p}=0.002$ and $\mathrm{r} 2=0.170, \mathrm{p}=0.009$, respectively. Despite the high amount of drug prescription, the implementation of the prevention community program reduces the number of falls $12 \%$ (fall incidence after the study 0.44 (SD 0.71).

After analyzing the data of the different drug groups, there was no relationship between calcium, vitamin D and antiresorptive intake in patients who suffered falls before and after the study. There was no relationship either between cardiovascular drugs intake and falls in individuals who took alpha-blockers. The participants who were prescribed beta-blockers had a fall incidence of 0.74 (SD 1.14) before the study, compared to those who were not on beta-blockers 0.42 (SD 0.86), with a mean difference of 0.33 (95\% CI, 0.05-0.60, $\mathrm{p}=0.023$ ). Nonetheless, at the end of the study, the participants on beta-blockers had a fall incidence 0.43 (SD 0.68) compared to those who were not on beta-blockers 0.45 (SD 0.72), with a mean difference of $0.03(95 \%$ CI, $0.20-0.25, \mathrm{p}=0.819)$. In this study we have not established a relationship between benzodiazepines and falls neither at the beginning of the study nor at the end. However, we have observed a relationship between falls and antidepressants. The fall incidence before the study was 1.22 (SD 1.09) compared to those who were not taking antidepressants 0.46 (SD 0.92), with a mean difference of 0.764 (95\% CI, 0.314-1.382, $\mathrm{p}=0.016$ ). Nevertheless, at the end of the study, participants who were on antidepressants had a fall incidence of 0.25 (SD 0.46) compared to those who were not taking them 0.45 (SD 0.72), with a mean difference of $0.20(95 \% \mathrm{CI}, 0.30-0.26, \mathrm{p}=0.426)$.

\section{Discussion}

In this study, age cannot be considered a risk factor for falling since there is no statistical relation between them [15]. Women presented a mean incidence fall 0.61 (SD 1.04) 12 months before the study compared to men 0.27 (SD 0.65, statistically significant [7]. However, at the end of the study, the incidence of falls between women 0.46 (SD 0.73) and men 0.43 (SD 0.69) is similar. This is probably due to the interventions carried out to improve the participants' health education throughout the 12 months.

Subjects participating in this study live in the community with a good functional health status. This data explains high scores in the Barthel index, the Tinetti scale and the MMSE. Thus, the quality of life perceived by the individuals is high, 7.2 (SD 2.3) which corresponds to the data obtained in the functional assessment scales, Consequently, risk factors related to balance alteration, dependence and cognitive impairment were not found [2,13-16].

The studied population presents a high prevalence of hypertension (59.4\%), although these figures are discreetly lower than in other cohorts $[57,58]$. The prevalence of type 2 diabetes mellitus $(24.55 \%)$ is similar to other studies $[59,60]$. The rest of the associated comorbidity does not differ from the usual prevalence figures in the elderly [61].

Differently to other studies which analyze risk factors for falling in the elderly, this sample presents a mean of 2.73 (SD 1.74) intrinsic risk factors, with a previous annual fall incidence rate of 0.5 (SD 0.94) and a previous fracture rate of 0.29 (0.74). These prevalence figures are lower and can be associated to living in a rural area and the good general health status of the participants [25,35-38].

Regarding drug prescription, there is no difference between men and women as described in other studies $[43,44]$. Several studies [14,17-24] establish a relationship between the number of drugs and falls. In this study that relation has been associated to specific drug groups. In fact, we can observe a higher number of falls in individuals who were taking beta-blockers and antidepressants. This has been described in previous articles [46,51] and has been attributed to the number of prescribed drugs, together with belonging to the drug groups that produce risk of falling.

We have also observed a higher fall incidence in hypertensive and diabetic participants, which has also been discussed in other articles [14, 17, 18,]. The alteration of the health status related to chronic cardiovascular pathologies, diabetes, etc., are risk factors related to falls in the elderly [19-22]. In these individuals we have seen a higher number of prescribed drugs, which can influence the number of falls. The number of drugs can be more important than taking antihypertensive medication, since individuals on antihypertensive drugs have less falls than those who do not take them. This fact can be due to drug interaction, which is related to the number of drugs prescribed and, at the same time, related to the incidence of falls [47-50,52]

To finish, we need to take into account that the sample does not present a high number of risk factors (2.73). However, the mean of the falls in the 12 months prior to the study was 0.50 , which does not correspond with what has previously been described in other studies [7], since the number of falls is high even though there are not many risk factors associated to this sample. This can be due to the fact that the participants of the study live in a rural area, present a relatively low mean age for a geriatric study and have a low prevalence of chronic diseases compared to the main fall prevention studies in the community $[2,19,26]$.

\section{Conclusions}

Women tend to have more falls than men, although this difference disappears at the end of the intervention.

Polypharmacy is directly related to falls. The number of drugs, as well as taking beta-blockers and antidepressants, increases the risk of falling.

We can conclude that a multidisciplinary community intervention contributes to the reduction of the fall incidence $(12 \%)$. This intervention program also reduces the incidence produced by a specific group of drugs. 


\section{REFERENCES}

[1] WHO. Caídas, Online available from http://www.who.int/mediacentre/factsheets/fs344/es/

[2] L. D. Gillespie, M. C. Robertson, W. J. Gillespie, C. Sherrington, S. Gates', L. M. Clemson, S. E. Lamb. Interventions for preventing falls in older people living in the community. Cochrane Database Systematic Review. Vol.12, No.9, 2012

[3] W. P. Berg, et al. Circumstances and consequences of falls in independent community-dwelling older adults. Age and Ageing, Vol.26,261-268, 1997

[4] F. Varas-Fabra F, E. Castro Martín, L. A. Pérula de Torres, M. J. Fernández Fernández, R. Ruiz Moral, I. Enciso Berge. Caídas en ancianos de la comunidad: prevalencia, consecuencias y factores asociados. Atencion Primaria. Vol. 38 , No. 8, 450-455, 2006

[5] S. R .Lord, D. McLean, G. Strathers. Physiological factors associated with injurious falls in older people living in the community. Gerontology, Vol.38,338-346, 1992

[6] J. Jagnoor, W. Suraweera, L. Keay, R.Q. Ivers, J.S. Thakur, G. Gururaj et al . Childhood and adult mortality from unintentional falls in India. Bull World Health Organ, Vol. 89, No.10,733-740, 2011

[7] M.E. Tinetti, M. Speechley, S.F. Ginter. Risk factors for falls among elderly persons living in the community. New England Jornal Medicine. Vol. 319, 1701-1707,1988

[8] J. M. Suelves, V. Martínez, A. Medina. Lesiones por caídas y factores asociados en personas mayores de Cataluña, España. (Spanish). Revista Panamericana de Salud Publica, Vol. 27, No. 1, 37-42, 2010

[9] Fundación MAPFRE. Estudio de la accidentabilidad de las personas mayores fuera del hogar. Fundación Mapfre. Madrid, 2011

[10] K. D. Hill, J. A. Schwarz, A. J. Kalogeropoulos et al. Fear of falling revisited. Archives of Physical Medicine and Rehabilitation, Vol.77,1025-1029, 1996

[11] K. E Ensrud. Epidemiology of fracture risk with advancing age. Journals of Gerontoly. Series A Biological Sciencies Medical Sciencies 2013 Jul 5. [Epub ahead of print].

[12] S.M. Bradle. Falls in older adults. Mount Sinai Journal Medicine, Vol. 78, No. 4, 590-595, 2011

[13] M.E. Tinetti, J. Doucette, E. Claus, et al. Risk factors for serious injury during falls by older persons in the community. Journal of the American Geriatrics Society, Vol. 43, No.11, 1214-21, 1995

[14] L.Z. Rubenstein, K.R. Josephson. The epidemiology of falls and syncope. Clinics in Geriatric Medicine, Vol. 18, 141-158, 2002

[15] E. L. Barr, C. Browning,S. R. Lord, H. B. Menz, H. Kendig. Foot and leg problems are important determinants of functional status in community dwelling older people. Disability and Rehabilitation, Vol. 19, No, 16, 917-923, 2005

[16] S. Iinattiniemi, J. Jokelainen, H. Luukinen . Falls risk among avery old home-dwelling population. Scandinavian Journal of Primary Health Care, Vol. 27, No.1, 25-30, 2009

[17] S. Iinattiniemi, J. Jokelainen, H. Luukinen . Falls risk among avery old home-dwelling population. Scandinavian Journal of Primary Health Care, Vol. 27, No.1, 25-30, 2009

[18] T. Villar San Pío, M.P. Mesa Lampré, A.B. Esteban Gimeno, A.C. Sanjoaquín Romero, E. Fernández Arín. Alteraciones de la marcha, inestabilidad y caídas. In: Sociedad Española en geriatría y gerontología. Tratado de geriatría para residentes. SEGG press, 199-209, Madrid; 2009

[19] A. C. Grundstrom, Clare E. Guse, and Peter M. Layde.Risk Factors for Falls and Fall-Related Injuries in Adults 85 Years of Age and Older. Archives of Gerontology and Geriatrics. Vol.54, No.3,421-428, 2012

[20] D. J. Thurman, J. A. Stevens, J. K. Rao. Quality Standards Subcommittee of the American Academy of, Neurology;. Practice parameter: Assessing patients in a neurology practice for risk of falls (an evidence-based review): report of the Quality Standards Subcommittee of the American Academy of Neurology. Neurology, Vol.70, No.6,473-479, 2008

[21] Miazgowski T, Krzyzanowska-Swiniarska B, Ogonowski J, Noworyta-Zietara M. [Does type 2 diabetes predispose to osteoporotic bone fractures? Endokrynologya Polsa, Vol. 59. No. 3:224-229, 2008

[22] J. Gribbin, R. Hubbard, J. Gladman, C. Smith, S.Lewis Risk of falls associated with antihypertensive medication: selfcontrolled case series. Pharmacoepidemiol Drug Saf Vol,20,879-884, 2011

[23] P. Ebeling. Clinical practice. Osteoporosis in men. New England Journal of Medicine, Vol. 358, No.14,1474-1482, 2008

[24] K. L. Stone, S. Ancoli-Israel, T. Blackwell T, et al. Actigraphy-measured sleep characteristics and risk of falls in older women. Archives of Internal Medicine, Vol.168. No.16,1768-1775, 2008

[25] T. Kojima, M. Akishita , T. Nakamura ,K. Nomura, S. Ogawa, K. Iijima, et al. Association of polypharmacy with fall risk among geriatric outpatients. Geriatrics \& Gerontolgy International, Vol.11, No. 4, 438-444, 2011

[26] A. Y. Chiu, S. Y. Au-Yeung, S. K. Lo. A comparison of four functional tests in discriminating fallers from non-fallers in older people. Disability and Rehabilitation, Vol.25,45-50, 2003

[27] E. Hommel, A. Ghazi, H.White . Minimal trauma fractures: lifting the specter of misconduct by identifying risk factors and planning for prevention. Journal of American Medical Directors Association, Vol. 13, No. 2, 180-186, 2012

[28] A.C. Scheffer, P. B.van Hensbroek, N. van Dijk N, J. S. Luitse, J. C. Goslings, R. H. Luigies, S. E. de Rooij. Risk factors associated with visiting or not visiting the accident \& emergency department after a fall. BMC, Health Service Reserarch, Vol 13, 286, 2013

[29] M. Anpalahan, S. G. Morrison, S. J. Gibson SJ. Hip fracture risk factors and the discriminability of hip fracture risk vary by age: A case-control study. Geriatrics and gerontology international, 2013, [Epub ahead of print

[30] J. Walker. Management of common fractures. Nursing Older 
People, Vol.25, No. 1, 30-37, 2013

[31] L. Papa, M. E. Mendes, C. F. Braga CF. Mild Traumatic Brain Injury among the Geriatric Population. Current Translational Geriatrics and Gerontology Reports, Vol 1, No. 3, 135-142, 2012

[32] W. Y. Yu, H. F. Hwang, M. H. Hu, C. Y. Chen, M. R: Lin. Effects of fall injury type and discharge placement on mortality, hospitalization, falls, and ADL changes among older people in Taiwan. Accident Analisis\& Prevention Vol, 50, 887-894, 2013

[33] J. C. Caballero GArcia, M. L. Remolar ML, Garcia R. Cuesta. Programa de intervención sobre el síndrome psicológico postcaída en el anciano. Revista Multidisciplinar Gerontologia, Vol. 10, No. 4, 249-258,2 000

[34] J. A. Stevens. Fatalities and injuries from falls among older adults - United States, 1993-2003 and 2001-2005. MMWR Vol.55, No. 45, 2006

[35] K.N. Freeland, A. N. Thompson, Y. Zhao Y, J. E. Leal, P. D. Mauldin, W.P. Moran. Medication use and associated risk of falling in a geriatric outpatient population. The Annals of Pharmacotheraphy, Vol. 46, No.9, 1188-1192, 2012

[36] G. Ziere, J. P. Dieleman, A. Hofman, H. A. P Pols, T. J. M. van der Cammen, B. H. C. Stricker. Polypharmacy and falls in the middle age and elderly population. British Journal of Clinic Pharmacoly, Vol. 61, No. 2, 218-223, 2006

[37] N. Van der Velde, B.H. Strieker, H. A. Pols, et al. Risk of falls after withdrawal of fall-risk-increasing drugs; a prospective cohort study. British Journal of Clinic Pharmacoly. Vol. 62, No.2, 232-237, 2007

[38] A. Kragh, S. Elmstahl, I. Atroshi. Older adults' medication use 6 months before and after hip fracture; a population based cohort study. Journal of the American Geriatrics, Vol. 59, No. 5, 863-868, 2011

[39] J. S. Bell, C. Mezrani, N. Blacker, T. LeBlanc, O. Frank, C. P. Alderman, et al. Anticholinergic and sedative medicines prescribing considerations for people with dementia. Australian Family Physician Vol.41, No.1-2, 45-49, 2012

[40] S. N. Hilmer, D. E, Mager, E. M. Simonsick, Y. Cao, S. M. Ling, B. G. Windham, et al. A drug burden index to define the functional burden of medications in older people. Archives of Internal Medicine, Vol. 167, No. 8, 781-787, 2007

[41] N. M. Wilson, S. N. Hilme, L. M. March, I. D. Cameron, S. R. Lord, M. J. Seibel, et al. Associations between drug burden index and falls in older people in residential aged care. Journal of the American Geriatrics Society, Vol. 59, No. $5,875-880,2011$

[42] A. Corsonello, C. Pedone, R. A. Incalzi RA. Agerelated pharmacokinetic and pharmacodynamic changes and related risk of adverse drug reactions. Current Medicine Chemistry, Vol. 17, No. 6, 571-584, 2010

[43] G.Trifirò, E. Spina. Age-related changes in pharmacodynamics: focus on drugs acting on central nervous and cardiovascular systems. Current Drug Metabolism, Vol 12, No. 7, 611-620, 2011

[44] F. Bloch, M. Thibaud, B. Dugue, C. Breque, A. S. Rigaud, G. Kemoun. Psychotropic drugs and falls in the elderly people: updated literature review and meta-analysis. Journal of Aging and Health, Vol. 23, No. 2, 329-346, 2011

[45] A. R. Huang, L. Mallet, C. M. Rochefort, T. Eguale, D. L. Buckeridge, R. Tamblyn. Medication-related falls in the elderly: causative factors and preventive strategies. Drugs \& Aging, Vol. 29, No. 5, 359-376, 2012

[46] R. M. Leipzig, R. G. Cumming, M. E. Tinetti. Drugs and falls in older people: a systematic review and meta-analysis: II. Cardiac and analgesic drugs. Journal of the American Geriatrics Society, Vol.47. No.1,40-50. 1999.

[47] N. Kerse, L. Flicker, J. J. Pfaff, et al. Falls, depression and antidepressants in later life: a large primary care appraisal. PLOS ONE. Vol. 3, No. 6, 2008

[48] E. Joe,B. Forester. Strategies to Manage Antidepressant Adverse Effects in the Elderly. Psychiatric times. 2010

[49] K. Kallin, L. Lundin-Olsson, J. Jensen, L. Nyberg , Y. Gustafson. Predisposing and precipitating factors for falls among older people in residential care. Public health, Vol 116. No. 5, 263-271, 2002

[50] L. Quach, F. M.Yang, S. D. Berry, E. Newton E, R. N. Jones,J. A. Burr, L. A. Lipsitz. Depression, antidepressants, and falls among community-dwelling elderly people: The MOBILIZE Boston Study. . Journals of Gerontoly. Series A Biological Sciencies Medical Sciencies. 2013 [Epub ahead of print

[51] B. Liu, G. Anderson, N. Mittmann, et al. Use of selective serotonin-reuptake inhibitors or tricyclic antidepressants and risk of hip fractures in elderly people. Lancet, Vol.351. No. 9112,1303-1307. 1998

[52] K. E. Ensrud, T. L. Blackwell,C. M Mangione, et al. Central nervous system-active medications and risk for falls in older women. Journal of the American Geriatrics Society, Vol. 50. No. 10, 1629-1637. 2002

[53] M. D. Valverde Carrillo, M. Flórez García, I. Sánchez Blanco. Escalas de actividades de la vida diaria. Rehabilitación, Vol.28, 377-388. 1994

[54] J.M. Casado, N. González, S. Moraleda, R. Orueta, J. Carmona, R.M. Gómez-Calcerrada. Calidad de vida relacionada con la salud en pacientes ancianos en atención primaria. Atención primaria, Vol.28, No.3, 167-173. 2001

[55] M. A. Alencar ,J. M. Dias, L. C. Figueiredo LC, R. C. Dias. Frailty and cognitive impairment among communitydwelling elderly. Archivos de neuropsiquiatria. Vol.71, No.6, 362-367. 2013

[56] A. Gutiérrez-Misis, M. T. Sánchez-Santos,J. R. Banegas, M. V. Zunzunegui, M. V, Castell, A. Otero A. Prevalence and incidence of hypertension in a population cohort of people aged 65 years or older in Spain. Journal of Hypertension. Vol. 29, No. 10, 1863-1870, 2011

[57] J. R. Banegas, F. Rodríguez-Artalejo, L. Ruilope, A. Graciani,M. Luque, J.J. de la Cruz-Troca, R. García-Robles, J. Tamargo, J. Rey-Calero, Juana. Hypertension magnitude and management in the elderly population of Spain. Journal of Hypertension, Vol 20. No. 11, 2157-2164, 2002

[58] C. C. Cowie, K. F. Rust, E. S. Ford,M. S. Eberhardt, D. D. Byrd-Holt,C. Li, et al. Full accounting of diabetes and prediabetes in the U.S. population in 1988-1994 and 2005-2006. 
Diabetes Care, Vol. 32, 287-294, 2009

[59] C. C. Cowie, K. F. Rust, E. S. Ford,M. S. Eberhardt, D. D. Byrd-Holt,C. Li, et al. Full accounting of diabetes and prediabetes in the U.S. population in 1988-1994 and 2005-2006. Diabetes Care, Vol. 32, 287-294, 2009

[60] S. Wild, G. Roglic, A. Green, R. Sicree, H. King .Global prevalence of diabetes: estimates for the year 2000 and projections for 2030. Diabetes Care. Vol. 27, 1047-1053, 2004

[61] F. Aslam, A. Haque, L. V. Lee, J. Foody. Hyperlipidemia in older adults. Clinics in Geriatrics Medicine. Vol. 25, No. 4, 591-606, 2009 